\title{
General Psychiatry Influencing factors of the neurodevelopment of high-risk infants
}

\author{
Yuan Tian, ${ }^{1}$ Chuncao Zhang, ${ }^{1}$ Guangjun Yu, ${ }^{1}$ Xiangying Hu, ${ }^{2}$ Zheng $\mathrm{Pu},{ }^{3}$ Liyu Ma ${ }^{4}$
}

To cite: Tian Y, Zhang C, Yu G, et al. Influencing factors of the neurodevelopment of high-risk infants. General Psychiatry 2018;31:e100034. doi:10.1136/ gpsych-2018-100034

Received 16 November 2018 Accepted 18 November 2018

\section{Check for updates}

C Author(s) (or their employer(s)) 2018. Re-use permitted under CC BY-NC. No commercial re-use. See rights and permissions. Published by BMJ.

${ }^{1}$ Department of Child Health Management, Children's Hospital of Shanghai, Shanghai, China

${ }^{2}$ Department of Child Healthcare, Shanghai Jingan Maternity and Infant Health Hospital, Shanghai, China

${ }^{3}$ Department of Child Healthcare, Shanghai Jiading Maternity and Infant Health Hospital, Shanghai, China

${ }^{4}$ Department of Child Healthcare, Shanghai Putuo Maternity and Infant Health Hospital, Shanghai, China

Correspondence to Professor Guangjun Yu; gjyu@shchildren.com.cn

\section{ABSTRACT}

Background High-risk infants refer to newborns exposed to high-risk factors in the prenatal, natal or postnatal period. High-risk infants are at high risk of developmental retardation, and early identification of developmental abnormalities plays a vital role in improving high-risk infants' quality of life.

Aims To describe the neurodevelopment of high-risk infants aged less than 1 year old, and to analyse the incidences and influencing factors of neurodevelopmental abnormalities in order to provide a basis for neurodevelopment monitoring and management of highrisk infants.

Methods High-risk infants born between January 2016 and December 2016 in the maternity and infant health hospitals of three districts in Shanghai were followed up. The Gesell Developmental Scale was used to assess the neurodevelopmental level at the time of recruitment (0-2 months) and at 9 months. Univariate and multivariate analyses of the influencing factors were conducted. Results 484 high-risk infants (male $51 \%$, female $49 \%$ ) with an average gestation age of $36.5 \pm 2.2$ weeks were recruited. At the time of recruitment, the average age was 2.1 (0.8) months, and the developmental quotient (DQ) scores of full-term high-risk infants in motor $(t=3.542$, $p=0.001)$, cognitive $(t=3.125, p=0.002)$, language $(t=3.189, p=0.002)$ and social $(t=3.316, p=0.001)$ areas were higher than those of preterm infants. The incidences of developmental abnormalities of full-term high-risk infants in motor $\left(\chi^{2}=9.452, p=0.002\right)$, cognitive $\left(\chi^{2}\right.$ $=6.258, p=0.012)$, language $\left(\chi^{2}=12.319, p=0.001\right)$ and social $\left(\chi^{2}=6.811, p=0.009\right)$ areas were lower than the preterm infants. At 9 months, there was no difference in the DQ scores and incidences of developmental abnormalities in four areas between full-term and preterm high-risk infants, and the incidence of developmental abnormalities was around $10 \%$.

Conclusion The incidence of neurodevelopmental abnormalities in high-risk infants aged less than 1 year old is high. Preterm birth and parental bad habits are significant factors affecting the neurodevelopment. Monitoring and early interventions help to improve highrisk infants' neurodevelopment.

\section{BACKGROUND}

High-risk infants refer to newborns exposed to high-risk factors in the prenatal, natal or postnatal period, ${ }^{1}$ mainly including preterm infants and full-term infants affected by one or more risk factors. The neurodevelopment of infants is affected by multiple factors, such as heredity, biology and environment. Preterm birth and low birth weight are known high-risk factors related to infants' neurodevelopmental abnormalities. ${ }^{2}$ Neurodevelopment monitoring of high-risk infants under the age of 3 years old is crucial for early identification of developmental abnormalities; therefore, early interventions which aim to improve motor and/or cognitive development could take the full advantage of neurological plasticity. ${ }^{3}$

In the current study, high-risk infants recruited from infant healthcare institutions in three districts of Shanghai were followed up. The Gesell Developmental Scale (GDS) was used to assess the neurodevelopment of high-risk infants shortly after birth and at 9 months of age. By identifying the influencing factors of the developmental abnormalities in motor, language, cognitive and social areas, this study provides basis for management and early intervention for high-risk infants.

\section{SUBJECTS AND METHODS}

\section{Subjects}

High-risk infants born between January 2016 and December 2016 were recruited in the maternity and infant health hospitals in three districts of Shanghai. The inclusion criteria ${ }^{1}$ were (1) high-risk factors during pregnancy and birth, such as preterm birth (gestational age [GA] $<37$ weeks), low birth weight (birth weight $\leq 2500 \mathrm{~g}$ ), giant infants (birth weight $>4000 \mathrm{~g}$ ), intrauterine developmental retardation, perinatal asphyxia and so forth; (2) birth complications, such as neonatal hypoxic ischaemic encephalopathy, hyperbilirubinaemia, intracranial haemorrhage, purulent meningitis and so forth; (3) and other high-risk factors, such as chronic lung disease, persistent feeding problems, persistent hypoglycaemia and so forth (figure 1).

\section{Methods}

Survey methods

High-risk infants that met the inclusion criteria were recruited and systematically 
648 infants born during 2016.01-2016.12 who received service from the infant health institutions in 3 districts of Shanghai.

Retrospective analysis of collected data, 484 infants who have complete GDS evaluation results at the time of recruitment or 9-month-old Inclusion Criteria :

1. High risk factors during pregnancy and birth: preterm birth (Gestational Age, GA $<37 w$ ), low birth weight (birth weight $\leqslant 2500$ g), giant infants (birth weight $>4000 \mathrm{~g}$ ), intrauterine developmental retardation, perinatal asphyxia etc;

2. Birth complications: such as neonatal hypoxicischemic encephalopathy, hyperbilirubinemia, intracranial hemorrhage, purulent meningitis etc;

3. Other high risk factors: such as chronic lung disease, persistent feeding problems, persistent hypoglycemia etc.

4. First stage of recruitment, age/corrected age $<2 \mathrm{~m} \mathrm{0d}$, second period(9month-old), age/corrected age between $8 \mathrm{~m} 15 \mathrm{~d}-9 \mathrm{~m}$ 15d

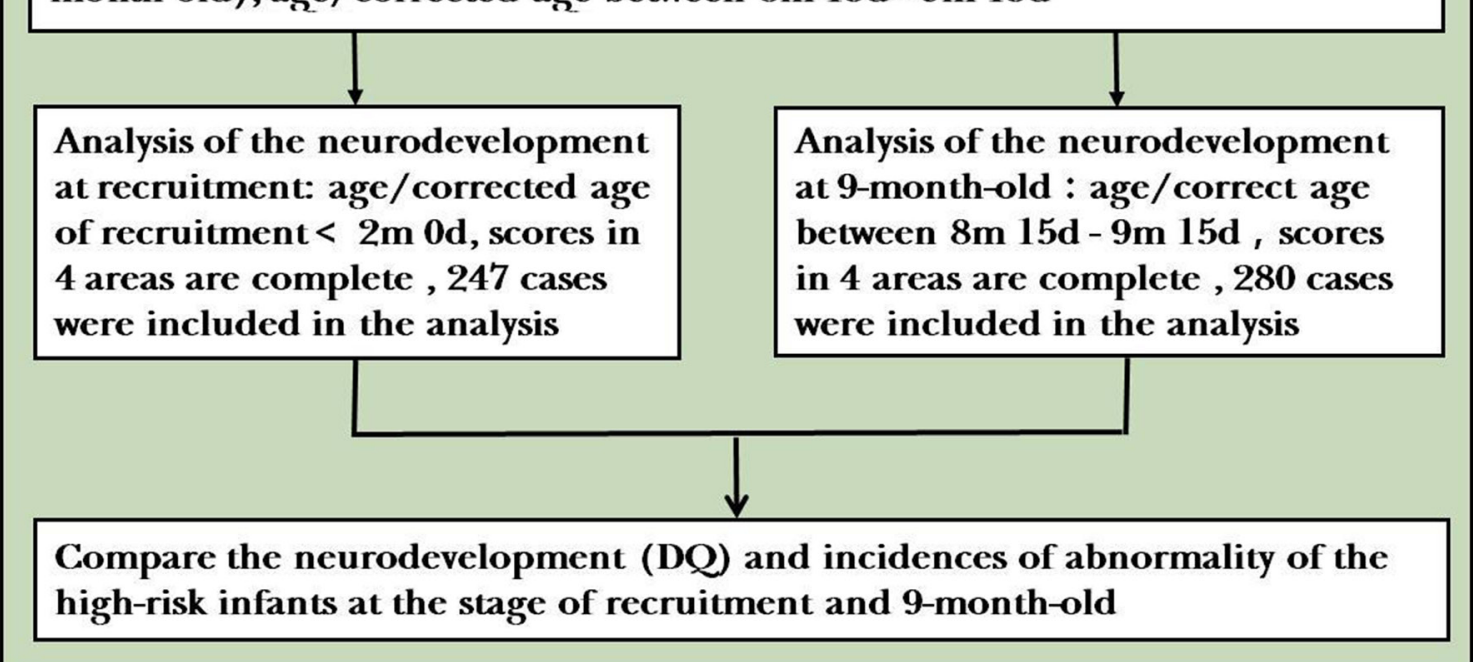

Figure 1 The inclusion and exclusion criteria of subjects and flow chart of research. DQ, developmental quotient; GA, gestational age; GDS, Gesell Developmental Scale.

followed up by the infant health department of the maternity and infant health hospitals in three districts of Shanghai ${ }^{4}$ : within $0-6$ months, the infants were followed up every month; and within 7-12 months, the infants were followed up every other month. Each follow-up included physical assessment, feeding guidance, neurodevelopment monitoring and instruction for early comprehensive intervention. At the time of recruitment $(<2$ months 0 day), basic information of the infants and their family was recorded, and the neurodevelopment was evaluated by trained paediatricians using the GDS. At 9 months of age ( 8 months 15 days-9 months 15 days), neurodevelopment was assessed again with the same scale. In the assessment of physical and neural development of preterm infants, their age was corrected by calculating the age from the expected date of birth.
Instrument

\section{General Information Questionnaire}

Basic information of high-risk infants was collected, including GA, birth weight, mode of delivery, birth complications and so forth. Information regarding parental general conditions, pregnancy and birth, smoking and drinking habits of the mother during pregnancy, and other health issues were also collected.

\section{Gesell Developmental Scale-Chinese Revised Version}

The GDS-Chinese Revised Version was used to assess neurodevelopment. GDS is a widely used classic psychometrical scale in China evaluating the development of child aged less than 6 years old. However, it was revised years ago. so the threshold value of the scale for assessing the development level is determined by the pass rate $(75 \%$ or $90 \%)$ of the 
Table 1 Comparison of DQ scores $(\mathrm{X}[\mathrm{s}])$ of preterm and full-term high-risk infants

\begin{tabular}{|c|c|c|c|c|}
\hline & \multicolumn{2}{|c|}{ Recruitment } & \multicolumn{2}{|c|}{ Age of 9 months } \\
\hline & $\begin{array}{l}\text { Preterm } \\
\text { infants }\end{array}$ & $\begin{array}{l}\text { Full-term } \\
\text { high-risk } \\
\text { infants }\end{array}$ & $\begin{array}{l}\text { Preterm } \\
\text { infants }\end{array}$ & $\begin{array}{l}\text { Full-term } \\
\text { high-risk } \\
\text { infants }\end{array}$ \\
\hline \multicolumn{5}{|l|}{ Motor area } \\
\hline $\mathrm{DQ}$ & $83.3(14.6)$ & $90.1(11.1)$ & $96.1(9.1)$ & $100.1(11.9)$ \\
\hline$t$ & 3.542 & & 3.208 & \\
\hline$P$ values & 0.001 & & 0.002 & \\
\hline \multicolumn{5}{|c|}{ Cognitive area } \\
\hline $\mathrm{DQ}$ & $80.2(14.1)$ & $86.3(13.3)$ & $94.9(8.1)$ & 95.7 (8.9) \\
\hline$t$ & 3.125 & & 0.643 & \\
\hline$P$ values & 0.002 & & 0.521 & \\
\hline \multicolumn{5}{|c|}{ Language area } \\
\hline $\mathrm{DQ}$ & $85.5(14.1)$ & $91.6(12.9)$ & $92.8(7.9)$ & $92.3(8.2)$ \\
\hline$t$ & 3.189 & & 0.417 & \\
\hline$P$ values & 0.002 & & 0.677 & \\
\hline \multicolumn{5}{|l|}{ Social area } \\
\hline $\mathrm{DQ}$ & $85.7(14.0)$ & $92.2(13.7)$ & $93.8(7.4)$ & $94.5(7.4)$ \\
\hline$t$ & 3.316 & & 0.788 & \\
\hline$P$ values & 0.001 & & 0.431 & \\
\hline
\end{tabular}

$\mathrm{DQ}$, developmental quotient.

item in the norm population. This scale has no reliability and validity information revealed in related literature. ${ }^{56}$ GDS can comprehensively assess the level of development in four developmental areas of children aged between 16 days and 6 years old, including motor area (gross and fine motor skills), cognitive area (analysis and synthesis of external stimuli and the ability of using previous experience to solve new problems), language area (listening, understanding and the ability in verbal communication) and social area (reaction to real social culture, social interaction and viability). The result is expressed by the developmental quotient (DQ): $\mathrm{DQ} \geq 86$ means normal, $\mathrm{DQ}<86$ means abnormal. This scale helps to identify infants' strengths and weaknesses in different developmental areas and provides a baseline for targeted education and training. ${ }^{57}$ The DQ of the different developmental areas indicates the infants' developmental level in different dimensions. Thus the sum or average score of the different areas could not indicate the general developmental level.

\section{Quality control}

Basic and follow-up information of high-risk infants was collected by a trained nurse and managed by a data management person. The assessment using GDS is performed by a paediatrician who was trained and qualified. All the assessments are performed in a standardized measuring room, in which the environment and facilities meet the assessment requirements.

\section{Data analysis}

Data cleaning, processing and analysis were performed in Excel 2016 and SPSS V.23.0. Descriptive statistics were performed for ratio and constituent ratio. $\overline{\mathrm{X}}(\mathrm{SD})$ and two-sample t-test were used and performed to describe and analyse the neurodevelopment of high-risk infants. $\chi^{2}$ test of univariate analysis was performed, and $p<0.05$ means having statistical significance. Logistic regression (forward: Logistic Regression (LR) method) of multivariate analysis was performed; when $p<0.05$ the variable was entered into the equation, and when $p>0.10$ the variable was excluded.

\section{RESULTS}

\section{General description of recruited high-risk infants}

In total there were 648 infants, who received service from the maternity and infant health hospitals in three districts of Shanghai, born between January 2016 and December 2016 . Four hundred and eighty-four infants whose GDS assessment results were complete at the time of recruitment or at 9 months were recruited. Within these 484 high-risk infants, $22.9 \%$ were from Jiading District, $46.7 \%$ from Jingan District and 30.4\% from Putuo District; $51.0 \%$ were male and $49.0 \%$ were female. Caesarean delivery was the major delivery method $(66.7 \%)$, vaginal delivery accounted for $31.8 \%$, and delivery aided by forceps and other methods accounted for $1.5 \%$. High-risk infants had an average GA of 36.5 (2.2) weeks and an average birth weight of 2727.6 (694.6) g. The average age of fathers was 33.6 (0.7) years, and the average age of mothers was 31.5 (4.3) years.

The composition of these 484 high-risk infants according to their $\mathrm{GA}^{8}$ and birth weight was as follows: early preterm infants ( 28 weeks $\leq \mathrm{GA}<32$ weeks) accounted for $1.4 \%$, mid-term preterm infants (32 weeks $\leq \mathrm{GA}<34$ weeks) accounted for $7.9 \%$, and late preterm infants (34 weeks $\leq \mathrm{GA}<37$ weeks) accounted for $42.1 \%$. Fullterm birth with low birthweight infants (GA $\geq 37$ weeks and birth weight $<2500 \mathrm{~g}$ ) accounted for $16.5 \%$, fullterm birth with normal birth weight (with other high-risk factors) accounted for $24.8 \%$, and full-term giant infants (GA $\geq 37$ weeks and birth weight $>4000 \mathrm{~g}$ ) accounted for $7.2 \%$.

\section{Neurodevelopment of high-risk infants with different GA}

The level of neurodevelopment was measured by the DQ scores for both preterm and full-term high-risk infants. At the time of recruitment, the preterm infants' average DQ score in each developmental area was lower than that of full-term infants. At the age of 9 months, the gap was reduced but the score in the motor area was still lower, as shown in table 1.

The incidence of neurodevelopment abnormalities in high-risk infants with different $\mathrm{GA}$

Comparing the incidences of neurodevelopmental abnormality $(\mathrm{DQ}<86)$ of preterm and full-term high-risk infants at the time of recruitment and at 9 months, it was shown that at the time of recruitment preterm infants' incidences 
Table 2 Incidence of neurodevelopmental abnormalities of different categories of high-risk infants (\%)

\begin{tabular}{|c|c|c|c|c|c|c|c|c|}
\hline & \multicolumn{2}{|c|}{$\begin{array}{l}\text { Preterm infants, } \\
\text { recruitment }\end{array}$} & \multicolumn{2}{|c|}{$\begin{array}{l}\text { Full-term high-risk } \\
\text { infants, recruitment }\end{array}$} & \multicolumn{2}{|c|}{$\begin{array}{l}\text { Preterm infants, } 9 \\
\text { months old }\end{array}$} & \multicolumn{2}{|c|}{$\begin{array}{l}\text { Full-term high-risk } \\
\text { infants, } 9 \text { months old }\end{array}$} \\
\hline & Normal & Abnormal & Normal & Abnormal & Normal & Abnormal & Normal & Abnormal \\
\hline \multicolumn{9}{|l|}{ Motor area } \\
\hline $\mathrm{n}(\%)$ & $84(48.0)$ & $91(52.0)$ & $50(69.4)$ & $22(30.6)$ & 91 (89.2) & $11(10.8)$ & 167 (93.8) & $11(6.2)$ \\
\hline$\chi^{2}$ & 9.452 & & & & 1.899 & & & \\
\hline$P$ values & 0.002 & & & & 0.168 & & & \\
\hline \multicolumn{9}{|c|}{ Cognitive area } \\
\hline n (\%) & 99 (56.6) & $76(43.4)$ & 53 (73.6) & $19(26.4)$ & $88(86.3)$ & 14 (13.7) & $154(86.5)$ & $24(13.5)$ \\
\hline$\chi^{2}$ & 6.258 & & & & 0.003 & & & \\
\hline$P$ values & 0.012 & & & & 0.955 & & & \\
\hline \multicolumn{9}{|c|}{ Language area } \\
\hline n (\%) & $62(35.4)$ & $113(64.6)$ & 43 (59.7) & $29(40.3)$ & $92(90.2)$ & $10(9.8)$ & $162(91.0)$ & $16(9.0)$ \\
\hline$\chi^{2}$ & 12.319 & & & & 0.051 & & & \\
\hline$P$ values & 0.001 & & & & 0.821 & & & \\
\hline \multicolumn{9}{|l|}{ Social area } \\
\hline $\mathrm{n}(\%)$ & 95 (54.3) & 80 (45.7) & 52 (72.2) & $20(27.8)$ & $92(90.2)$ & $10(9.8)$ & $160(89.9)$ & $18(10.1)$ \\
\hline$\chi^{2}$ & 6.811 & & & & 0.007 & & & \\
\hline$P$ values & 0.009 & & & & 0.934 & & & \\
\hline
\end{tabular}

of developmental abnormalities in the motor, cognitive, language and social areas were, respectively, $21.4 \%, 17 \%$, $24.3 \%$ and $17.9 \%$ higher than those of full-term high-risk infants, and these differences were statistically significant. At the age of 9 months, the incidences of developmental abnormalities of preterm infants dropped, and there was no significant difference with the full-term high-risk infants. However, at the age of 9 months, the incidence of developmental abnormalities in each area was still about $10 \%$ for both preterm and full-term high-risk infants, as shown in table 2.

The influencing factors of neurodevelopmental abnormalities in 9-month-old high-risk infants

Pearson's $\chi^{2}$ test was conducted to analyse the influencing factors of neurodevelopmental abnormalities in 9-month-old high-risk infants. The statistically significant factors include the following: advanced maternal age (age of the mother at birth $>35, \chi^{2}=5.944, p=0.017$ ) and drinking habit of the father $\left(\chi^{2}=4.329, p=0.036\right)$ are factors related to abnormalities in the motor area; advanced maternal age $\left(\chi^{2}=6.047, p=0.015\right)$, the mother watching television (TV) for a long time during pregnancy ( $\geq 5$ hours $/$ day, $\chi^{2}=8.507$, $p=0.018$ ), advanced age of the father (age of the father at birth $\left.>40, \chi^{2}=7.627, p=0.009\right)$ and drinking habit of the father $\left(\chi^{2}=17.058, p=0.013\right)$ are related to abnormalities in the cognitive area; and smoking habit of the mother $\left(\chi^{2}=13.215, p=0.027\right)$ and the mother watching TV for a long time during pregnancy ( $\geq 5$ hours/day, $\chi^{2}=10.545, p=0.011$ ) are factors related to abnormalities in the language area.

In the multivariate analysis, the factors with statistical significance in the univariate analysis were used as the independent variables, and the abnormalities in the four areas of the GDS evaluation $(\mathrm{DQ}<86)$ were taken as dependent variables. The results are shown in table 3 . Preterm delivery, advanced age of the mother and drinking habit of the father are factors affecting the motor area of 9-month-old high-risk infants; advanced age of the mother, the mother watching TV $\geq 5$ hours per day during pregnancy and drinking habit of the father are factors affecting the cognitive area; smoking habit of the mother is the factor affecting the language area (table 3 ).

\section{DISCUSSION}

\section{Main findings}

In this study, the preterm infants' incidences of neurodevelopmental abnormalities in different areas can reach as high as $50 \%$ shortly after birth and are still about $10 \%$ at the age of 9 months. Consistent with other related research, preterm birth has a significant effect on neurodevelopment, especially in the motor area. ${ }^{9}$ The development of obstetric and neonatal intensive care technology has consistently increased the survival rate of high-risk infants. Now in China, the survival rate of super-preterm infants with GA $\leq 28$ weeks can reach $78 \% .{ }^{10}$ However, those preterm infants who survived still face severe developmental challenges. A long-term follow-up of preterm infants showed that about $50 \%$ of preterm infants with GA $<32$ weeks have one or more developmental problems, and the rate of mild neurodevelopmental disorders can be as high as $50 \% .{ }^{11}$ Preterm infants with low birth weight have higher risk of developing attention deficit disorder and learning difficulties at school age. ${ }^{2}{ }^{12}$ It is 


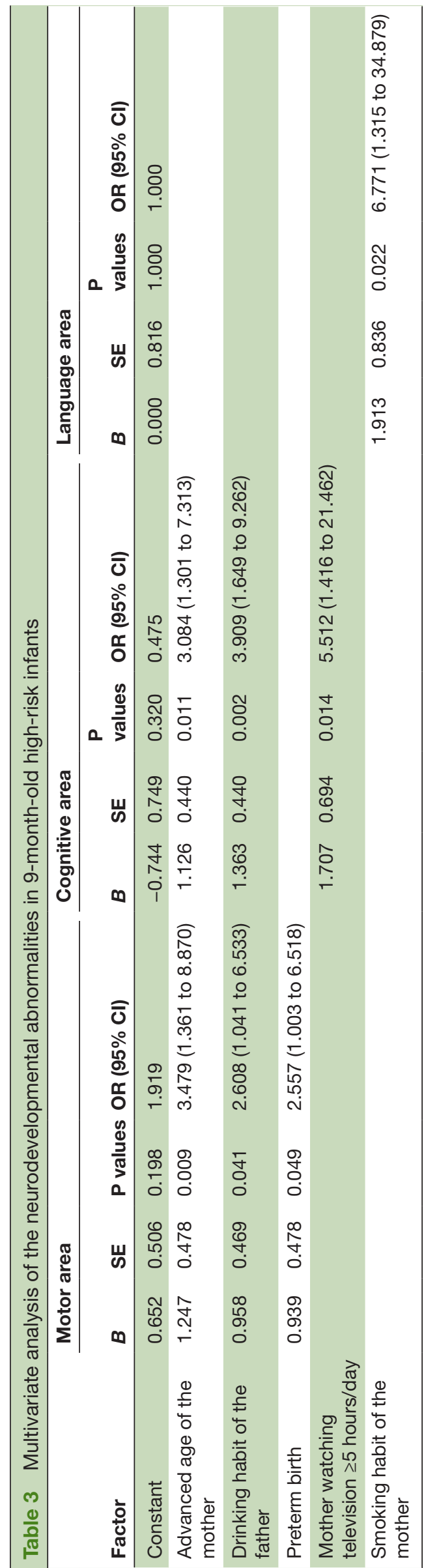

because preterm infants leave the mother's body prematurely, so the brain cell proliferation decreases, causing the relatively low brain weight. The earlier the birth and the lighter the birth weight, the higher the risk of mental retardation and learning disabilities and so forth. ${ }^{13} 14$

In addition to preterm birth, parental bad habits also affect high-risk infants' neurodevelopment in the motor and cognitive areas. It is known that parental bad habits such as drinking and smoking have a negative impact on children's health. Parents watching TV for a long time means less parent-child interaction time, and then it affects the time and quality of the implementation of early intervention. Studies have shown that, ${ }^{1}$ in addition to biological factors such as preterm birth and birth complications and so forth, family, social, environmental and other non-biological factors often interact with biological factors, affecting and predicting the long-term functional development of high-risk infants.

A systematic review of early interventions for preterm and low birthweight infants clearly states that development monitoring and early intervention have positive effects on improving high-risk infants' short-term motor and cognitive developmental outcomes, lasting from infancy $^{3}$ until the age of 36 months. ${ }^{15}$ Our study also suggests that although the 9-month-old high-risk infants' incidence of developmental abnormalities is still about $10 \%$, it has decreased significantly compared with that at the time of recruitment, which indicates that close development monitoring and early comprehensive intervention of high-risk infants at the county-level infant healthcare institutions contribute to better prognosis.

\section{Limitations}

Although in this study all data on the follow-up of highrisk infants were carefully collected and cleaned, the accuracy and completeness of the data were still limited compared with those of well-designed studies. The GDS is a widely used classic scale for infants' development assessment in China. However, the scale is not updated according to the developmental characteristics and levels of contemporary children. Therefore, the timeliness of this scale is relatively poor. Since early intervention for high-risk infants is a requirement of the district-level (counties) infant health institutions, all high-risk infants who were followed up in three districts (counties) in this study received systematic management and early intervention. Thus there is no control group without systematic follow-up and intervention. Due to the limitations of the research design, it is unable to conduct more detailed and indepth multivariate analyses.

\section{Implications}

High-risk infants are at high risk of developmental disorders. The practice of follow-up of high-risk infants at district-level (counties) infant health institutions indicates that high-risk infants still face higher risk of developmental disorders within the year of birth. Long-term follow-up is required in order to observe long-term 
outcomes. Biological factors such as preterm birth and low birth weight are hard to change after birth, but actively carrying out parental health education during pregnancy and infancy, changing parental bad habits, improving the family environment and conducting early interventions can help to improve the development of high-risk infants.

Contributors XH, ZP and LM collected and processed the data of this study. CZ did part of the data analysis. GY provided suggestions in modifying this paper.

Funding This study was funded by the 'Three-Year Action Plan for Strengthening the Public Health System in Shanghai (2015-2017) - Management of High-risk infants with Multidisciplinary Cooperation', project number: GWIV-19.

Competing interests None declared.

Patient consent for publication Not required.

Ethics approval The Shanghai Children's Hospital Ethics Committee has confirmed that there is no negative ethical impact and violation of related ethical issues in this study before its commencement.

Provenance and peer review Not commissioned; externally peer reviewed.

Data sharing statement № additional data are available.

Open access This is an open access article distributed in accordance with the Creative Commons Attribution Non Commercial (CC BY-NC 4.0) license, which permits others to distribute, remix, adapt, build upon this work non-commercially, and license their derivative works on different terms, provided the original work is properly cited and the use is non-commercial. See: http://creativecommons.org/ licenses/by-nc/4.0

\section{REFERENCES}

1. Chen R, Zhao Z, Liu X. Children's Health (Fifth Edition) M. Jiangsu: Phoenix Science and Technology Press of Jiangsu, 2017.

2. Vohr B. Long-term outcomes of moderately preterm, late preterm, and early term infants. Clin Perinatol 2013;40:739-51.
3. Spittle A, Orton J, Anderson PJ, et al. Early developmental intervention programmes provided post hospital discharge to prevent motor and cognitive impairment in preterm infants. Cochrane Database Syst Rev 2015;(11):CD005495.

4. Tian Y, Zhang Y, Chen F, et al. The effect of multidisciplinary management system of preterm infants on the neurodevelopmental outcomes of preterm infants discharged from neonatal intensive care unit [J]. Chinese Journal of Child Health Care 2018;26:294-7.

5. Xu S, Huang H, Zhang J. The progress of research and application of diagnostic developmental evaluation scale for infants [J]. Chinese Journal of Child Health Care 2010;11:859-61.

6. Yang Y. Children's Developmental Rating Scale M. 1. Beijing: People's Guardian Press, 2016.

7. Chen Y, Chen G. Introduction and comparison of several diagnostic criteria and scales of mental retardation [J]. Chinese Journal of Applied Chinical Pediatrics 2007;12:958-60.

8. Goldenberg RL, Culhane JF, lams JD, et al. Epidemiology and causes of preterm birth. The Lancet 2008;371:75-84.

9. You J, Wang S, Wnag J. Monitoring of the neuropsychological behavior development in preterm and low birth weight infants[J]. Chinese Journal of Child Health Care 2016;06:662-4.

10. Zhou W. Retrospective analysis of major clinical problems in very preterm infants and preparation of human umbilical cord blood mesenchymal stem cells $D$. Pediatric of Southern Medical University, 2013.

11. Saigal S, Doyle LW. An overview of mortality and sequelae of preterm birth from infancy to adulthood. Lancet 2008;371:261-9.

12. Wei X, Han Y. Progress of research on early intervention of preterm infants in China [J]. Chinese Journal of Reproductive Health 2003;14:254-5

13. Johnson S, Strauss V, Gilmore C, et al. Learning disabilities among extremely preterm children without neurosensory impairment: Comorbidity, neuropsychological profiles and scholastic outcomes. Early Hum Dev 2016;103:69-75.

14. Johnson S, Wolke D, Hennessy E, et al. Educational outcomes in extremely preterm children: neuropsychological correlates and predictors of attainment. Dev Neuropsychol 2011;36:74-95.

15. Vanderveen JA, Bassler D, Robertson CM, et al. Early interventions involving parents to improve neurodevelopmental outcomes of premature infants: a meta-analysis. J Perinatol 2009;29:343-51.

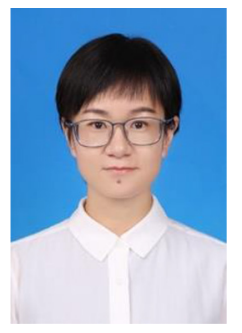

Yuan Tian received her bachelor's degree from the Department of Preventive Medicine of the School of Public Health of Xinjiang Medical University in 2004. She received her master's and doctor's degree from the department of maternal and child health of School of Public Health of Fudan University in 2007 and 2012. Since August 2012, she worked as a public health physician (women and children health care) at Children's Hospital of Shanghai. Currently she is the director of the Health Management Department of Children's Hospital of Shanghai and is mainly engaged in child health management. Her research interest is comprehensive management and early intervention for high-risk infants. 